\title{
Lesión ulcerada en el paladar en un paciente inmunodeprimido
}

\section{Palatal ulcer in immunocompromised patient}

\author{
Antonela Dusso $^{1}$, Andrea Mesa Bernal ${ }^{2}$, Mariana Andreani ${ }^{3}$ y Claudia Frola ${ }^{4}$
}

1 Médica Instructora de Residentes, Unidad de Dermatología

2 Médica Concurrente, Unidad de Dermatología

${ }^{3}$ Bioquímica de Planta, Área Micología

${ }^{4}$ Médica de Planta, División de Infectología

Unidad de Dermatología, Hospital de Agudos Dr. Juan A. Fernán-

dez, Ciudad Autónoma de Buenos Aires, Argentina

\author{
Contacto del autor: Antonela Dusso \\ E-mail: antodusso@gmail.com \\ Fecha de trabajo recibido: $6 / 4 / 2020$ \\ Fecha de trabajo aceptado: 8/6/2020 \\ Conflicto de interés: las autoras declaran que no existe conflicto \\ de interés.
}

Dermatol. Argent. 2020, 26 (2): 87-88

\section{CASO CLÍ́NICO}

Paciente de 57 ańos, oriundo de la provincia de Entre Ríos, con antecedente de infección por HIV diagnosticada hace 7 ańos, con mala adherencia a la terapia antirretroviral (TARV), en mal estado inmunológico (recuento de linfocitos T CD4+: 71 cél./ $\mu \mathrm{L}$ y carga viral: 432.837 copias $/ \mathrm{mL}$ ). Consultó por una lesión eritematosa ulcerovegetante, con bordes irregulares, que comprometía el paladar duro y blando, con predominio en el lado izquierdo de 7 meses de evolución, indolora, acompañada de adenopatías bilaterales submaxilares móviles, fiebre, astenia y tos productiva. No presentaba otras lesiones en el resto del examen físico dermatológico (Foto 1).

Como diagnósticos diferenciales se consideraron: causas infecciosas (histoplasmosis, paracoccidioidomicosis, leishmaniasis), neoplásicas (carcinoma espinoce-

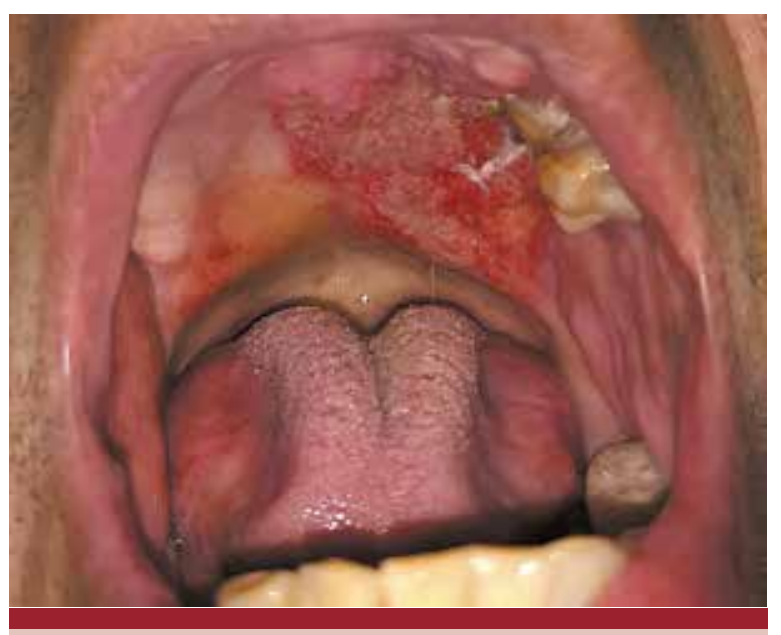

FOT0 1: Lesión ulcerovegetante en el paladar. lular, adenocarcinoma quístico, linfoma plasmoblástico) y traumáticas.

\section{ESTUDIOS COMPLEMENTARIOS}

Radiografía de tórax: infiltrados difusos bilaterales. Laboratorio: $\mathrm{Hb}$ 11,3 g/dL, VSG $41 \mathrm{~mm}$, resto sin particularidades.

Examen directo-microscopia con coloración de Giemsa (100X): levaduras intramacrófagos, coloreadas polarmente ("coloración en casquete"), rodeadas de un halo claro (Foto 2).

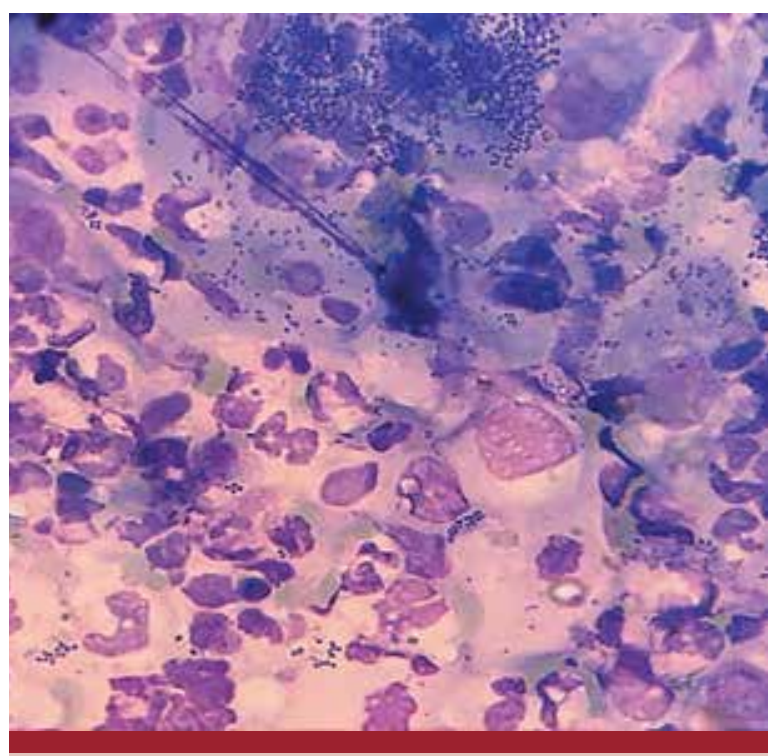

F0T0 2: Múltiples levaduras en el citoplasma de células fagocíticas (tinción de Giemsa, 100X). 
Estudio histopatológico de la lesión: proceso inflamatorio, con abundantes histiocitos, en cuyos citoplasmas se hallan elementos pequeños redondeados, con núcleo central rodeado por un halo claro, positivos con tinción de Grocott.

\section{DIAGNÓSTICO}

Histoplasmosis diseminada crónica en el contexto de inmunosupresión por HIV.

\section{EVOLUCIÓN}

El paciente inició tratamiento de inducción con anfotericina $B$ desoxicolato $(0,7 \mathrm{mg} / \mathrm{kg} / \mathrm{día})$, por vía intravenosa, durante 2 semanas. Posteriormente, continuó con itraconazol por 12 meses, como fase de consolidación (200 mg, 3 veces al día por 3 días y, luego, $200 \mathrm{mg}$ dos veces al día por vía oral). Al finalizar la fase de inducción, se instauró la terapia antirretroviral. El paciente evolucionó de forma favorable, con signos de cicatrización a los 30 días (Foto 3).

Es importante destacar que el examen directo orientó a un diagnóstico micológico rápido por microscopia, lo que permitió iniciar el tratamiento antifúngico de manera precoz.

\section{COMENTARIOS}

La histoplasmosis es una micosis sistémica endémica producida por el hongo dimorfo Histoplasma capsulatum. Mientras que en las personas inmunocompetentes la mayor parte de las infecciones son asintomáticas o subclínicas, en los pacientes con deterioro de la inmunidad celular predominan las formas diseminadas ${ }^{1}$. Es reconocida como la segunda micosis sistémica oportunista en Argentina, después de la criptococosis en pacientes HIV positivos².

\section{BIBLIOGRAFÍA}

1. Negroni R. Manifestaciones cutáneas mucosas de la histoplasmosis diseminada (histoplasmosis clásica o histoplasmosis capsulati). Dermatol Argent 2008;14:104-112.

2. Frola C, Bermejo V, Spadaccini L, Guelfand L, et ál. Impacto de la histoplasmosis diseminada en pacientes HIV positivos. Actualizaciones en Sida e Infectología 2013;21:37-41.

3. Negroni R, Arechavala Al, Maiolo El. Histoplasmosis clásica en inmunocomprometidos. Med Cutan lber Lat Am 2010;38:59-69.

4. López Daneri A, Arechavala A, lovannitti C, Mujica MT.

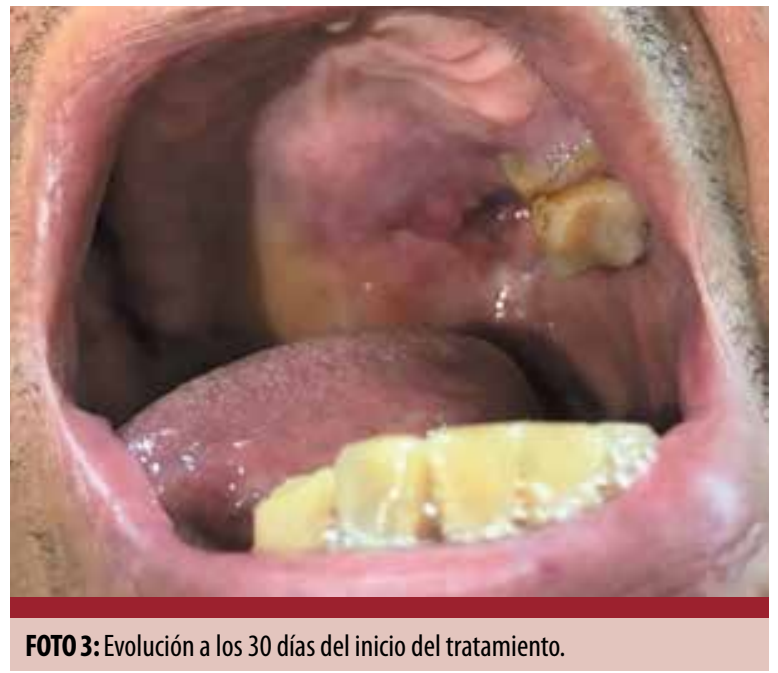

Entre las manifestaciones cutáneas se pueden observar pápulas moluscoides o ulceradas cubiertas por una costra serohemática, nódulos que evolucionan a gomas y úlceras. Las lesiones cutáneas están presentes hasta en un $80 \%$ de los pacientes con histoplasmosis diseminada en Latinoamérica, por lo que el examen directo representa una herramienta sencilla, rápida y económica para arribar a un diagnóstico temprano ${ }^{3,4}$. Con menor frecuencia, se observan lesiones mucosas que se presentan como úlceras de fondo granuloso ${ }^{1,3}$.

La elección del tratamiento se fundamenta en la presentación y el estado clínico del paciente. En huéspedes inmunosuprimidos, con formas diseminadas severas, compromiso del sistema nervioso central o afección multisistémica, se recomienda anfotericina B como terapia de inducción y, luego, itraconazol como fase de consolidación ${ }^{3,5,6}$.

Histoplasmosis diseminada en pacientes HIV/SIDA. Buenos Aires, 2009-2014. Medicina (Buenos Aires) 2016;76:332-337.

5. Wheat LJ, Freifeld AG, Kleiman MB, Baddley JW, et ál. Clinical practice guidelines for the management of patients with histoplasmosis: 2007 update by the Infectious Diseases Society of America. Clin Infect Dis 2007;45:807-825.

6. Myint T, Leedy N, Villacorta Cari E, Wheat LJ. HIV-Associated Histoplasmosis: Current Perspectives. HIV AIDS (Auckl) 2020;12:113-125. 